\title{
Disentangling patient and public involvement in healthcare decisions: Why the difference matters
}

Mio Fredriksson, PhD, Uppsala University

Jonathan Tritter, DPhil, Aston University

\begin{abstract}
Patient and public involvement has become an integral aspect of many developed health systems and is judged to be an essential driver for reform. However, little attention has been paid to the distinctions between patients and the public, and the views of patients are often seen to encompass those of the general public. Using an ideal-type approach, we analyse crucial distinctions between patient involvement and public involvement using examples from Sweden and England. We highlight that patients have sectional interests as health services users in contrast to the citizen who engage as public policy agent reflecting societal interests. Patients draw on experiential knowledge and focus on output legitimacy and performance accountability, aim at typical representativeness, and a direct responsiveness to individual needs and preferences. In contrast, the public contributes with collective perspectives generated from diversity, centers on input legitimacy achieved through statistical representativeness, democratic accountability and indirect responsiveness to general citizen preferences. Thus, using patients as proxies for the public fails to achieve intended goals and benefits of involvement. We conclude that understanding and measuring the impact of patient and public involvement can only develop with the application of a clearer comprehension of the differences.
\end{abstract}




\section{Key words}

Patient and public involvement; Citizen participation; Patient empowerment; Sectional and societal interest; Legitimacy; Accountability; Representativeness; Responsiveness

\section{Introduction}

Patient and public involvement (PPI), that is lay involvement in healthcare decisions, has become an increasingly important aspect of European health systems (Florin and Dixon 2004; Tritter 2009; Coulter 2013). User involvement, public participation and patient empowerment are other expressions that are used when referring to lay involvement. To what extent these different concepts refer to similar or different involvement ideologies, actions and objectives is not clearly established (Forbat et al. 2009; Mockford et al. 2011). For the purposes of this article we use Tritter's definition (2009: 267), "Ways in which patients can draw on their experience and members of the public can apply their priorities to the evaluation, development, organization and delivery of health services." Various goals are associated with PPI, for example empowerment of patients and disadvantaged service users, strengthening the democratic process, enhancing accountability and legitimacy as well as improved service delivery effectiveness, care quality, individual health outcomes, public health, system responsiveness and user satisfaction (Coulter 2013; van Thiel and Stolk 2013; Crawford et al. 2003; Coulter 2005).

There are many models that try to grasp the complexity of PPI (Tritter 2009; Forbat et al. 2009; Rowe and Frewer 2005; Carman et al. 2013; Oliver et al. 2008). These models, however, do not specifically address the distinction 
between involving patients and involving the public; a distinction Coulter 2005 sees as that between what we want and can articulate as individual patients, and the collective aspirations of citizens or members of the public. Patients and members of the public have, for instance, been found to value health states differently (Peeters and Stiggelbout 2010). Yet, in involvement research and even more so in the design of involvement policies, PPI is often used without drawing a distinction between patients and the public -variously referred to as users, consumers, lay people, potential patients, and citizens. The inattentive grouping of patients and the public is problematic (Warsh 2014; Christiaens et al. 2012) as it may lead to the design and implementation of policies that fail to achieve the intended goals and result in mismatched expectations (Forbat et al. 2009; Charles and DeMaio 1993; Hogg 1999). This in turn, can make people less willing to be involved and even be counterproductive and undermine trust in public institutions (OECD 2001). Furthermore, the confusion in the terminology is inappropriate as patients and citizens - as we demonstrate in this article may have contrasting or competing interests. The distinction is readily apparent in the contrast between a cancer patient (or carer) whose primary interest is ensuring their individual access to the most recent drugs and treatment and citizens whose interests relate to issues of equality of access and cost-effectiveness.

This paper presents a theoretical discussion and exploration of the difference between involving patients and involving the public in healthcare decisions in publicly-funded healthcare systems. In doing so, we also illustrate why it is inappropriate to use patients as proxies for the public in healthcare decisions. We take healthcare decisions to include the range from individual patient decisions about treatment to members of the public identifying health needs and priorities for their community (see e.g., Florin and Dixon 2004). Similarly 
to Warsh (2014), our argument is based on the premise that patient involvement and public involvement is not based on the same justifications; patient involvement is a reaction to medical paternalism and the patient's limited capacity to manage their own health, whereas public involvement draws on democratic theory and is a response to the democratic deficit, voter apathy and declining trust in public institutions.

Using an ideal type approach, "a hypothetical description of the pure characteristics of a phenomenon or object" (Calhoun 2002), we explore how the distinction between involving patients and the public can be understood. In Table 1 we illustrate this distinction in relation to role, perspective and decision focus, involvement resource, unit of action, type of interest, and representativeness, and furthermore in terms of three common goals of involvement; legitimacy, accountability and responsiveness. Thus we do not explicitly address distinctions in relation to goals such as improved health outcomes and efficiency, or discuss different involvement mechanisms or tools or their variations in potential impact. Exploring the distinction and including literature and ideal-type characteristics, we have used a snowballing approach (such as pursuing references of references) (Greenhalgh and Peacock 2005) based on previous literature on patient and public involvement in healthcare as well as on literature on citizen and user participation more broadly. Our aspiration with the presented ideal type distinction (which is not exhaustive but can be expanded with additional elements and characteristics) is to support the systematic thinking about differences between involving patients and involving the public.

To illustrate the implications we draw on examples from England and Sweden. In Europe, England is at the forefront of understanding the distinctions between 
patients and the public in research as well as in actual policy-making (Florin and Dixon 2004; Coulter 2005; NHS England 2013), whereas the insight in Sweden is less explicit. Both countries have tax-funded national health service systems based on common principles and in both countries the political rhetoric has encouraged patient and public involvement in health care. However, in Sweden the responsibility for funding and provision of healthcare is decentralized to regional authorities that are democratically governed and elected. This distinction creates the opportunity to explore the difference between patient involvement and public involvement in healthcare within a common underlying health system structure: a national health system rather than social health insurance or market-based systems.

Table 1. The ideal type distinction between patients and the public

\begin{tabular}{|c|c|c|}
\hline & Patients & The public \\
\hline Role & $\begin{array}{l}\text { Health services user. Role based on } \\
\text { illness or potential illness: right to } \\
\text { access, information, consent, free } \\
\text { choice, privacy, confidentiality, etc. }\end{array}$ & $\begin{array}{l}\text { Public policy agent. Role based on } \\
\text { citizenship: rights, duties, } \\
\text { participation, and identity. }\end{array}$ \\
\hline $\begin{array}{l}\text { Perspective and } \\
\text { decision focus }\end{array}$ & $\begin{array}{l}\text { The health and well-being of oneself, } \\
\text { family, friends or particular interest } \\
\text { groups. Decisions about own } \\
\text { treatment and care: improvements in } \\
\text { clinical care setting. }\end{array}$ & $\begin{array}{l}\text { Welfare or well-being of the general } \\
\text { public. Strategic decisions about } \\
\text { health services and policy at local or } \\
\text { national level: improvements at the } \\
\text { organisational level. }\end{array}$ \\
\hline $\begin{array}{l}\text { Involvement } \\
\text { resource }\end{array}$ & $\begin{array}{l}\text { Experiential knowledge: generated } \\
\text { from being a service user }\end{array}$ & $\begin{array}{l}\text { Collective perspectives generated } \\
\text { from diversity }\end{array}$ \\
\hline Unit of action & Individual and/or collective & Collective and/or individual \\
\hline Type of interest & $\begin{array}{l}\text { Sectional: individual or group } \\
\text { engaged around a single issue. Cause } \\
\text { groups }\end{array}$ & $\begin{array}{l}\text { Societal: independent of interest of } \\
\text { individuals. Public interest groups }\end{array}$ \\
\hline Legitimacy claim & $\begin{array}{l}\text { Internal. Output (effectiveness in } \\
\text { terms of quality of result); input } \\
\text { (policy formulation and decision } \\
\text { making). }\end{array}$ & $\begin{array}{l}\text { External. Input (policy formulation } \\
\text { and decision making); output } \\
\text { (effectiveness in terms of quality of } \\
\text { result). }\end{array}$ \\
\hline $\begin{array}{l}\text { Representativeness } \\
\text { claim }\end{array}$ & Typical, substantive & Statistical/descriptive, symbolic \\
\hline Accountability claim & Performance, social & Political and democratic, social \\
\hline $\begin{array}{l}\text { Responsiveness } \\
\text { claim }\end{array}$ & $\begin{array}{l}\text { Direct: provider and staff compliance } \\
\text { with the patient's values and } \\
\text { preferences }\end{array}$ & $\begin{array}{l}\text { Indirect: policymakers' general } \\
\text { compliance with citizen preferences } \\
\text { and expectations of the health system } \\
\text { and public policy }\end{array}$ \\
\hline
\end{tabular}

Two traditions: democratic theory and medical paternalism 
Although amalgamated into the joint term PPI, the justification for patient involvement and public involvement is based on two different traditions.

The public refers to "ordinary people in general; the community" (Oxford Dictionaries 2015). The public is largely made up of citizens (although some members of the public such as refugees and recent immigrants may not be citizens). Support for greater public involvement generally draws on democratic theory and principles of citizenship (Warsh 2014; OECD 2001). Citizenship includes the core features of rights, duties, participation and identity (Lister and Pia 2008) and the role of citizen is based on the legitimacy of legal, political and social membership of the community (Callaghan and Wistow 2006). It involves a relationship between individuals and political communities (Lister and Pia 2008), making political participation - activities intended to influence government action but not necessarily targeting political authorities (Kaase 2011) - an important part of citizenship. The rising demand for stronger involvement of citizens in the public sphere is a response to the democratic deficit, for instance in health systems such the as the English National Health Service (NHS) (Coulter 2013). The rationale for this approach is that public ownership and funding of the health service entitles citizens to be involved in decision-making and to have their voices heard (The Centre for Public Scrutiny 2007). As citizens, people are asked to see beyond their own rights and interests and take on wider community responsibilities (Brannan et al. 2006). The aim of citizen involvement, or public involvement, "stretches beyond consumerist notions of individual satisfaction to ensure responsiveness and accountability in the context of public funding" (Callaghan and Wistow 2006). 
Patients are "people with particular health problems who may be taking medicines or receiving treatment", and everyone is at some time a patient (Hogg 1999 p. 6). Patients have rights rather than duties as exemplified by the European Charter of patients' rights; for example the right to access, information, consent, free choice, privacy and confidentiality (European Charter of patients' rights 2002). In practice the patient interest, to a greater or lesser extent is shared by their carer/relatives who may act as their representatives or participate in decisions. Involvement of family and friends is one key feature of patient-centeredness (Coulter 2013). The support for greater patient involvement in clinical settings is a reaction to medical paternalism (Warsh 2014; Hogg 1999), where doctors are presented as the experts and patients are expected to trust them to act in their best interest and comply with their advice as passive recipients of care rather than active partners (Coulter 2005). It has been argued that medical paternalism undermines the individual's capacity to manage the own health and that health outcomes are expected to improve when patients take on a more active role in partnership with health professionals; for instance, by learning how to monitor and manage long term conditions (Coulter 2013). Patient involvement is thus an effort to enhance autonomy and resist the medical paternalism that has defined healthcare delivery in the UK (Hogg 1999), and perhaps even more so in Sweden which repeatedly ranks low on measures of patient centeredness (Docteur and Coulter 2012). In both countries, as well as in the rest of Europe, patient choice is probably the most widely implemented variant of patient involvement (Dent and Pahor 2015) and has been embraced to improve care and empower patients (Fredriksson 2013) as part of broader approaches to the commodification and marketisation of health services. Patients are assumed to 'vote with their feet' and choose the best quality healthcare (The Centre for 
Public Scrutiny 2007). Choice is a "consumerist" form of involvement that focuses on the opportunity of exit, (see further Accountability and responsiveness) in contrast to "deliberative" and "participatory" forms of involvement that build on the opportunity to participate in decision-making (voice) and to engage in the delivery of treatments and services in partnership with health professionals (co-production) (Dent and Pahor2015). As consumers, service users have "a legitimate interest in provision on a personal basis" and thus patient choice is predicated on individual's acting in their own interest which may be in tension with the needs of the population and the public. Increasing the economic power of the individual patient through mechanisms such as patient choice not only increases patients' chances of influencing healthcare but also has a negative impact on voice and the process of making binding collective decisions in matters of common interest (see e.g., Fredriksson 2013). Furthermore, cost containment is a key concern behind policies such as patient choice (Dent and Pahor 2015). In the English NHS the political rhetoric justifying this approach has included limiting healthcare expenditure, producing higher quality services and increasing local responsiveness (Tritter 2009; Tritter et al., 2009).

\section{Patient and the public: An introduction to differences}

Are patients and the public distinct groups? Perhaps more accurately than seeing patients and the public as separate groups, patients and the public have different roles in health care decision-making (Forbat et al. 2009; Christiaens et al. 2012; Charles and DeMaio 1993). An individual may occupy different roles in relation to the health sector and adopt the role of patient or citizen/member of the public in a specific context. Thus, it is not a distinction between people 
but between interests (Anderson et al. 2002) (see the next section for a detailed discussion of interests). The role adopted depends on the question being addressed and on the perspective chosen: that of a health services user or that of public policy agent (Charles and DeMaio 1993). For example, a person in good health may use the health service sparingly and have limited experience as a patient, but may still want to influence how public resources are distributed (The Centre for Public Scrutiny 2007). A person diagnosed and treated for cancer 20 years previously may still regard himself or herself as a 'cancer patient' but their experience of care probably has little relevance to the current provision of services yet they will still approach decisions about health services differently than a member of the public. The distinct perspectives of the health service user and the public policy agent have different bearings on decisions regarding treatment, service delivery, and broad macro- or system-level issues such as prioritisation (Charles and DeMaio 1993). A complicating factor discussing the different roles is that 'the patient' is a sub-category of 'the public', while the inverse relationship does not apply; patients can be public policy agents but not all public policy agents are patients.

The perspective of the health services user concerns the individual patient's narrowly defined interests or a specific patient group's interests. Coulter suggests that primarily what patients want is effective treatment delivered by trusted professionals, emotional support, empathy and respect, participation in decisions and respect for preferences, and continuity of care and smooth transitions between types and loci of care (Coulter 2013). Thus, patient involvement focuses on people's participation in decisions about their own treatment and care or to a group of patients helping to shape a particular

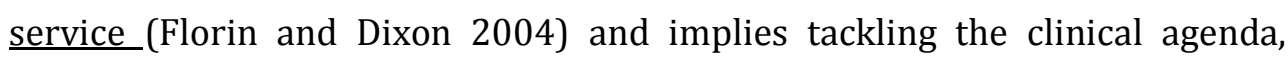
changing the culture of care and making improvements in clinical care (Coulter 
and Ellins 2006). Coulter (2013, p.5) goes on to argue that in general, patients "care more about the quality of their everyday interactions with health professionals than about how the service is organized". Benefits associated with patient involvement are ensuring appropriate treatment and care, improving health outcomes and safety and reducing risk factors, complaints as well as preventing ill-health (Coulter and Ellins 2006).

By contrast, the perspective of the public policy agent incorporates a broader public interest (Charles and DeMaio 1993). The public is primarily concerned with ensuring affordable treatment and care free at the point of use, universal coverage, geographical and social equity, and transparency, accountability, and opportunity to influence policy decisions. Thus, a debate regarding planning, management and values is accessed when involving the public who often respond strongly to perceived threats to a health system such as the English NHS and the values it is seen to represent (Coulter 2006; Coulter 2013). Public involvement focuses on participation in strategic decisions regarding health services and policy at both the local and national levels-for instance, about the configuration of services or setting priorities (Forbat et al. 2009); the aim of this form of involvement is to make improvements at the organisational level (Crawford et al. 2003). The benefits of public involvement include improving service design, determining priorities, managing demand, meeting expectations and strengthening accountability (Coulter 2006). While Coulter (2006) recognises the distinction between patient and public involvement she sees the former as far more important as a mechanism for cultural and systemic change.

Thus, benefits associated with PPI are both extrinsic and intrinsic (Brannan et al. 2006): patient involvement and public involvement are both a means to an end (technocratic (Martin 2008)) and an end in and of themselves (empowering 
(Christiaens et al. 2012)). Thus apart from the notion that both those paying for services - often referred to as citizens - and those affected by services patients - should have a right to be engaged in service design and development (The Centre for Public Scrutiny 2007), PPI is often linked to efforts to improve quality and effectiveness of services. The foundational idea is that lay people contribute to decisions with something distinct from policy makers and medical experts. In relation to health professionals that are deemed to rely on objective knowledge, patients are expected to express a more subjective knowledge relying on their own or others experiences of being service users (Charles and DeMaio 1993; Coulter 2013) and "their real-life experience of being affected by a disease and its current therapeutic environment" (EMA 2011). This type of non-expert knowledge is sometimes referred to as 'experiential knowledge' (Nordin 2000; Van Thiel and Stolk 2013). Thus, patient expertise tends to be context and temporally specific as it rests on their own particular experience of illness, which according to Charles and De Maio (1993, p. 884) puts the patient "in the best position to place a value on the benefits and costs of living with the potential consequences of various treatments." Patients contributing from the perspective of experience - being experts about themselves (Socialstyrelsen n.d.) - are widely regarded as a key aspect of improving health care quality (Haxby et al. 2010). In contrast, the public contributes with local perspectives, values and attitudes that are not based on expert or experiential knowledge (Hendriks 2011) but rather based on civic knowledge and the experience generated from membership and participation in particular communities often mediated through particular characteristics such as belonging to a marginal group (Brown 2006). The public also contributes with a 'disinterested' perspective (Marent et al. 2015). Members of the public are expected to articulate "goals and values different from those of most experts and 
politicians" (Brown 2006 p. 204) and citizen input is necessary to reflect societal values, to include multiple perspectives (van Thiel and Stolk 2013) and to articulate the perspectives of diverse social groups (Brown 2006). Thus giving citizens access to the policy arena is intended to contribute to the perspectives needed to solve complex social issues (Boedeltje and Cornips 2004), for instance through participatory budgeting (NHS England, 2014).

Although public involvement is usually portrayed as a collective endeavour and patient involvement as an individual effort, this view is too narrow as patients as well as members of the public can be involved individually or collectively, and through representatives (Tritter 2009). A group of patients or a patient association may help shape a particular service or policy (Haxby et al. 2010; Florin and Dixon 2004). Conversely, citizens may also relate to public services and decision-makers as individuals, in addition to being part of organised groups such as civil society organisations (Hogg 1999). However, (Contandriopoulos et al. 2004) argues that in contrast to 'the public's voices' (citizens' representatives, community organisations, citizens' groups etcetera), the 'ordinary citizen' is largely absent from the involvement process.

\section{Interest: Sectional and societal}

Coulter (Coulter 2006) points out that patients using the health service may want different things than citizens and taxpayers hope for; patients and the public have different interests. Simply put, interest means "the advantage or benefit of a person or group" (Oxford Dictionaries 2015) and is intimately connected to the notion of political and social power (Dowding 2011). The increased focus on PPI signals a shift in position concerning "who has the right 
to make what health care decisions in whose interests" (Charles and DeMaio 1993, p. 883).

Interests may be individual as well as collective, long-term or short term, true or expressed, may be of equal or unequal import, and may be subjective or objective. We focus on the distinction between societal (public) and sectional (self-interest or vested interest) interest (Pleasence and Maclean 1998). The perspective of the health services user concerns the individual patient's narrowly defined interests or particularistic interests (Marent et al. 2015); the health and well-being of oneself, but also of family, friends or interest groups (a specific patient group or a patient association) with which the individual identifies (OECD 2001). This is a sectional interest that is based on the interests of individuals alone, or individuals engaged around a single issue. The perspective of the public policy agent takes account of a broader public interest and the common good (Marent et al. 2015), that is the welfare or well-being of the general public (Dictionary.com. 2015), rather than particularistic goals tied to specific interest (Charles and DeMaio 1993). This is a societal interest that is independent of the interests of the individuals making up that structure. Societal interest requires that people set aside their direct self-interest (Funk 2000) and particularistic preferences based on e.g. health condition (Tenbensel 2010), and is compromised by too extensive a presence of sectional interest (apart from patient interests also business and professional bodies) in the policy-making arena (Trappenburg 2005). The OECD asserts that when citizens have a direct interest in an issue - for example as patients with a long-term condition - they become stakeholders. Their direct interest makes them important to involve, but it is also important to balance the involvement of stakeholders by involving the general public; all citizens concerned directly or through citizen organisations (OECD 2001). 
In a defined public, sectional and societal interests co-exist and conflict. It is easy to see that the dialysis patients in a Swedish region may argue that all hospitals in the area need a dialysis unit (to avoid long distance travel and inconvenience) while the public would like to concentrate such services to one hospital to increase cost-effectiveness. Nevertheless, it may be questioned whether there is one societal interest. To define public interest is a notoriously difficult task as the public sphere is always constituted by conflict that stems from diverging public, or societal, interests (Fraser 1997), that may be linked to characteristics such as age, gender, profession, linguistic or ethnic background (OECD 2001). It is necessary to create ways of resolving conflicts between different public interests (that is the different interests that advocate a broader common good in contrast to particularistic interests based on the unique experience of being a user), and reaching public-spirited solutions; democratic institutions and procedures being the preferred method in most countries. Citizen participation and deliberation have been promoted as effective mechanisms for resolving public conflict and preventing resistance. Involvement based on deliberation permits individuals from different backgrounds, with different interests and values to put forward their arguments, listen, discuss, persuade and reach well-informed decisions (Abelson et al. 2002; Boedeltje and Cornips 2004).

Yet, even if a particular action or intervention may greatly benefit a substantial number of people, it does not mean that it is truly in the public interest. Alternative actions or interventions may promote far greater benefit. A specific medical intervention may benefit a substantial number of patients (e.g. Gastric Bypass Surgery), but health promotion efforts changing people's lifestyle may instead promote far greater benefits, that is, be in the true public interest (Pleasence and Maclean 1998). This means that individualistic solutions such 
as patient choice are not well suited in determining public interest. The simple aggregation of individual patient preferences does not equate to a public view. Moreover, many researchers suggest that it is too simplistic to assume that patients have consistent and defined expectations and are able to formulate their current and future needs, even if they have the appropriate information (Schlesinger 2010).

Interest groups: Cause groups and public interest groups

Interest groups often take part in PPI activities. There are different kinds of interest groups (Encyclopædia Britannica 2015); patient organizations may be referred to as cause groups as they represent a segment of society - sectional interests - and their primary purpose is not economic but to promote a particular cause. They represent the interest of their members. One example is the Swedish Diabetes Association, Sweden's voice for people with diabetes, which protects their common interests: to minimise the consequences of the disease. In contrast, public interest groups promote issues of general public concern such as Swedish FAMNA, The national organization for idea-based health and social care. Public interest groups try to advance the interests beyond their membership - societal interest. Although most interest groups are not formed for political purposes but for creating advantages for a common cause, when they act in the political sphere their goal is to achieve favourable policy outcomes. This means that PPI initiatives that enhance involvement via patient associations and similar collectives may promote a sectional perspective and influence decisions in their own favour rather than a wider societal perspective. Organisations concerned with general health issues often have limited membership as people prefer involvement in groups representing 
their specific interest through which they are more likely to influence policy and practice (Hogg 1999).

\section{Legitimacy and representativeness}

To increase legitimacy is one of the purposes of PPI. Legitimacy is a complex concept. (Suchman 1995, p. 574) defines legitimacy as "a generalized perception or assumption that the actions of an entity are desirable, proper, or appropriate within some socially constructed system of norms, values, beliefs, and definitions".

For our purpose, it is instructive to distinguish between two types of legitimacy: the participation-oriented legitimacy of input and the performance-oriented legitimacy of output (Schmidt 2013; Scharpf 1997). Input legitimacy centres on the process of policy formulation and decision-making and is associated with responsiveness to citizen concerns as a result of participation. Output legitimacy centres on the effectiveness of public policies and services and focuses on the quality of results.

PPI is often framed as making the decisions and the policy process more legitimate by involving the public (input-legitimacy), whereas involving the patient focuses on achieving legitimate results such as appropriate treatment and care, patient satisfaction, reduced costs and improved individual health outcomes (out-put legitimacy) (Snyder 2014). Nonetheless, citizens also have opinions on policy output, in particular on the effectiveness of achieving the goals citizens collectively care about (Scharpf 1997), for example universal coverage and access, disease prevention and value for money. Conversely, patients also care about input, in particular how the patient's perspective is 
taken into individual treatment decisions; this is however being more about responsiveness to patient's values and preferences.

Another way of depicting how PPI contributes to legitimacy is to use a distinction between external and internal legitimacy (Nedlund and Garpenby 2008). In the PPI setting, external legitimacy refers to the relationship between the health service and the public as payers, whereas internal legitimacy refers to the relationship between the different actors in a health system, for instance the health professionals and the patients. Thus, involving the public is a way to enhance the external legitimacy and involving the patients is a way to enhance internal legitimacy.

\section{From indirect to direct involvement: Concerns about representativeness}

The ability to produce political decisions that are legitimate is one of the core values of democracy. Delegitimising of the wider political system, for instance a professionalisation of politics that makes it less representative, has increased the need for other forms of public participation alongside elections (Gibson et al. 2012). Today both Swedish and British citizens trust appointed power holders such as doctors and police officers more than their elected representatives (Rothstein 2009; Ipsos MORI 2014). Governments, such as those in Sweden and the UK, have responded to the perceived democratic deficit by introducing other more direct forms of participation that are intended to provide "real opportunities" (Boedeltje and Cornips 2004) to influence policy decisions. This implies a move from indirect to direct involvement (Callahan 2007). 
Direct involvement is a basic democratic mechanism that is able to generate legitimacy (Rothstein 2009). Direct involvement through PPI initiatives can be classified as non-electoral forms of representation (representative claims that cannot be determined by election); such forms include citizen's forums and juries, focus groups and advocacy groups. There are two types of non-electoral representation. First, agents who self-authorise: typically interest groups and philanthropic foundations making "representative claims on behalf of interests and values they believe should have an impact" (Urbinati and Warren 2008, p. 403). Such representation is often targeted and issue specific and respond to constituencies that are not territorially based but rather idea and identity based. In relation to PPI, patient associations are often the most influential and powerful example of a self-authorising agent. In Sweden, for example, selfauthorising agents are regularly asked to comment on legislative proposals and function as important discussant partners in national and local policy processes (Myndigheten för vårdanalys 2015).

Second, governments are increasingly making room for citizen representatives in nonelected bodies such as citizen panels, focus groups and deliberative forums (70). In the UK, the National Institute for Health and Care Excellence operates a Citizen's Council (73) although this has been criticized. One reason for establishing these new bodies is that the elected representatives need to be informed about what the public want them to represent, as "votes in themselves are information-poor" (Urbinati and Warren 2008, p. 402). Citizens are selected or self-selected and typically supplements elected representative bodies or administrative bodies, rather than serving as alternatives. In these bodies citizens serve in a representative capacity representing other citizens (Warren 2008). Thus, the growth of direct involvement has drawn attention to the concept of representation (Urbinati and Warren 2008). 
Warren (2008) argues that although involvement initiatives are usually categorised as participatory democracy efforts, "only a tiny percentage" of citizens are actually involved, and therefore these are misleadingly categorised. PPI-initiatives such as citizen's panels do not mean that most citizens are engaged in controlling its activities. It is more accurate to say that a few citizens actively serve as representatives of a potential constituency making the most important aspect of these PPI initiatives their representative qualities. As many of the new involvement forms are based on self-selection, they tend to favour those who are better educated and wealthier (de Freitas and Martin 2015; Warren 2008). Not all can participate in what Parkinson (75, p. 180) refers to as "the demanding procedural requirements which deliberation imposes on participants". This may be described in terms of a paradox, in which case, increased opportunities for participation may increase the overrepresentation of the already well represented. This may lead to increased political inequality (Cain 2003; Michels and Graaf 2010) suggesting the need for disadvantaged or vulnerable groups to be involved using modified participation methods (Christiaens et al. 2012).

In fact, the concern about representativeness is one of the primary barriers to involving patients and the public (Martin 2008) and concerns about representativeness have been found to undermine the legitimacy of views expressed by involved lay representatives. The discussion of representativeness is complicated as there are many types. Involving patients generally aims to achieve typical representativeness - "an individual who is typical of others or who has shared similar experiences" (Crawford et al. 2003). For example, people with a long-term condition - and this type of representation may be referred to as substantive; the representative takes actions on the behalf of, and in the interest of, those represented (Swers 2005). 
Patients with a specific condition often question the capacity of those without experience of the same condition to represent them effectively (Martin 2008). In addition, it has been argued, although not unchallenged (Staley 2013), that one of the paradoxes of involvement is that those recruited for their experience become experts with the support and training they need to be able to effectively take part in the process (Ives et al. 2012).

In contrast, public involvement aims to achieve statistical representativeness a representative sample selected to reflect the characteristics of the total population. Thus involving the public is about descriptive representation (Pitkin 1967) focusing on who the representative is rather than what (s)he wants (Brown 2006), and may be described as symbolic (Swers 2005). As people cannot be held accountable for who they are, accountability in this type of public involvement activities becomes problematic (Brown 2006).

\section{Accountability and responsiveness}

One of the oft-mentioned purposes of PPI-initiatives is to increase accountability and in the UK is sometimes linked to high profile cases of medical malpractice such as children's heart surgery in Bristol (Bristol Royal Infirmary Inquiry 2001). Accountability includes the two cornerstones of answerability and sanctions (Brinkerhoff 2003); being able to provide an account in relation to a challenge and also that an inadequate account has consequences. As with legitimacy, accountability contains a high degree of complexity and the type of accountability - for example forum, actor, conduct, obligation (Bovens 2006) is rarely specified. In health systems there are two types of arenas that are important in relation to PPI and accountability. The first is the policy-making arena, where accountability centres on the political justification for decisions 
and actions in relation to the public (Day and Klein 1987). The second is the service provision arena where accountability concerns managers and executives who are responsible for the implementation of agreed policies. In this arena, health professionals and service providers are primarily accountable to their patients.

Bovens (2007) defines accountability as a relationship between an actor (often a public institution or a government agency) and a forum (such as the general public) in which the actor has an obligation to explain and justify the conduct, the forum can pose questions and pass judgment, and the actor can be sanctioned. The public can, for example, sanction the government by withdrawing electoral support, and dissatisfied service users can sanction a provider by talking to the media (so called 'softer' sanctions). Health care staff can be subject to formal complaints and lose their license to practice. The option to 'exit' a provider that is not living up to the standards is in the literature often mentioned as an accountability mechanism, even if accountability is usually understood as 'voice' rather than 'choice' (Mulgan 2000); voice allows dissatisfied service users to complain, seek information and rectification from an organisation. Markets provide 'exit' mechanisms for securing responsiveness (Mulgan 2011) but the opportunity to exit in most health systems is heavily constrained by the availability of alternative provision (Tritter 2010).

A threefold typology based on different domains has been used to describe accountability in healthcare (Coulter 2013; Anon 2007; Brinkerhoff 2003), which illustrates a certain overlap between the domains of financial accountability, performance accountability and, political and democratic accountability (compare with Bovens typology: political, legal, administrative, 
professional, and social accountability (Bovens 2007)). Financial accountability - which overlaps with Boven's administrative accountability - is primarily procedural and refers to, for example, financial control and management, and overall value for money and cost effectiveness; aspects relevant primarily to members of the public. For patients, the concern with the appropriate use of resources tends to be focused on a particular condition or population and relate to access to treatments such as the latest cancer drug (Hopkinson and Richardson 2015).

Accountability for performance focuses on the service outputs and results of public agencies and programs (Brinkerhoff 2003) and involves performance measurements, evaluations and professional competence (the latter overlaps with Boven's concept of professional accountability). This type of accountability is primarily directed towards responsiveness to patients as users of services (The Centre for Public Scrutiny 2007). Patients are primarily interested in holding providers and health professionals accountable for the received treatment and its outcomes (The Centre for Public Scrutiny 2007), also referred to as product or outcome accountability (Day and Klein 1987). In addition to the public's interest in accountability for the procedural aspects of health care policy and delivery (see political and democratic accountability), the public is also interested in accountability for the product, or content of the health service: that is the general performance of the health service. In line with this, most health systems have introduced transparency measures such as public disclosure of performance measurements to strengthen accountability. The yearly regional comparisons of quality and efficiency in Swedish health care containing 186 indicators in 2014 - is but one example. However, transparency, while often used as a synonym for accountability, is insufficient to constitute accountability. Transparency is an important prerequisite for accountability 
and may provide forums with relevant information, but full accountability requires the capacity of a forum to impose sanctions on the actor. As in the Swedish regional comparisons, sanction possibilities are usually absent or undefined in benchmarks, satisfaction surveys and the like (Mulgan 2000; Bovens 2007).

Performance accountability is linked to political and democratic accountability, as one of the criteria for performance is responsiveness to the public as citizens and taxpayers. Political and democratic accountability involves the institutions, procedures, and mechanisms that are in place to ensure that the authorities represent citizens' interests, respond to societal needs and concerns, and deliver on electoral promises such as to deliver efficiency, quality of care and equity (Brinkerhoff 2003; Brinkerhoff 2004; Bovens 2007). Thus, voting is the main avenue for generating this type of accountability and ultimately, but few elections are decided solely on issues related to health so a strong desire to hold politicians accountable for one issue may be diluted by other issues citizens find important. A central idea in the decentralised Swedish health system is that democratic accountability is easier to achieve at the local level because of the proximity of citizens and elected representatives and public officials, and because politicians are elected to manage healthcare specifically (Amnå 2006). In contrast, Hogg (1999) has criticised the British NHS for only having elected representation of citizens at the national level and the vast distance between people's everyday experiences and national policy-making makes it difficult for people to make themselves heard or influence policy and implementation.

As a response to the perceived lack of trust in government institutions discussed earlier, many European health systems have tried to establish direct and explicit accountability relations between public agencies and clients, 
citizens, and civil society. This is what Bovens (2007) refer to as social accountability; meaning that patients and the public and their associations are seen as relevant stakeholders in policymaking and in rendering account from agencies and individual public managers such as hospital mangers and health care staff. However, as Bovens argues, the extent to which the more direct and explicit mechanisms are full accountability mechanisms is unclear as the possibility of judgment and sanctioning is often lacking.

In fact, accountability is often used to describe the extent to which governments pursue the wishes or needs of their citizens (Mulgan 2000). More accurately, however, this refers to responsiveness, to which accountability is a means (Mulgan 2011). Responsiveness can be expressed in relation to the public: "the provision of accessible, efficient and citizen-oriented public services that effectively address the needs and expectations of the public" (OECD 2013, p. 29). This is an indirect responsiveness relationship that concerns general compliance with popular demands and involves public agencies, political representatives and the public (Mulgan 2000). Responses to changing citizen preferences and expectations are normally not immediate. The second responsiveness relationship is between agencies providing services and the needs of their clients. Responsiveness to patients, for example to their physical, emotional and social needs as well as to values and preferences, is important because care experiences can influence the effectiveness of treatment and health outcomes (Coulter 2013). Those involved in service delivery are increasingly urged to respond directly and immediately to their clients' expressed needs, thus providing direct responsiveness. Efforts to make patients more involved generally focus on strengthening this direct relationship by creating a client focus and competition between providers, an approach presented as incentivising providers to be responsive to consumer wishes but 
implemented using patient choice. Thus, organisational changes towards greater client focus and concern for service quality may contribute to greater responsiveness but are not accountability procedures (Mulgan 2000). It has even been argued that 'horizontalization' of public service provision makes accountability harder (Lieberherr 2015) and may be responsibilising instead of empowering (Fotaki 2011).

Thus, importantly Bovens (2007) argues that accountability should be distinguished from responsiveness and participation. Responsiveness to needs and preferences among patients and the public and participatory forms of involvement may increase the system's legitimacy, but they do not constitute accountability. In its core sense accountability is retrospective or ex post; it is concerned with information and explanation about past actions (Mulgan 2011). What is sometimes described as prospective accountability, or ex ante, is rather about creating responsiveness to the needs of citizens or about making legitimate decisions. In fact, it has been questioned whether or not patient and public involvement in decision-making compromises genuine accountability opportunities as those supposed to pose questions and pass judgment are involved in the actual decisions (The Centre for Public Scrutiny 2007).

\section{Conclusions}

The vast majority of the scholarly discussion and practical application of patient and public involvement is based on assumptions of commonality between patients and the public rather than recognising their distinctions. Further, such discussions focus on the nature of the involvement activity and the views and satisfaction of those involved rather than examining the distinctions between those who are involved and the impact of the activity on policy and practice. We have argued that as ideal types, patients and the public have different roles, 
perspectives, experiences, expectations and interests and should not be grouped together. In practice, the distinction is less clear cut as in relation to health services each individual may occupy several roles simultaneously. The patient role is a subcategory of the wider role of citizen or member of the public; although we prioritize our own interactions with staff and caregivers when we visit the GP or a hospital we are still members of the public (Coulter 2013).

In essence, however, patient involvement is a reaction to medical paternalism and the patient's limited capacity to manage their own health. Public involvement, on the other hand, is a response to the democratic deficit, voter apathy and declining trust in public institutions. This has implications for reconsidering the nature of the doctor-patient relationships for health systems and particularly publicly funded health systems. The interaction is different when the patient is also recognised as a public policy agent (a citizen) and not solely concerned with their individual health needs. An illustration might be the refusal by a patient of antibiotics on the basis that this increases the likelihood of increasing antimicrobial resistance.

Having identified a range of characteristics that have been used to advocate for patient and public involvement, we have analysed some distinctions between patients and the public. Based on sectional and societal interest respectively, claims of legitimacy, representation, accountability and responsiveness differ between patients and the public. The implications of our analysis is an affirmation of the need for public involvement to be conceptualised and operationalised differently than patient involvement and to acknowledge that citizens have valid and relevant views that may be at odds with those of patients, but that still need to be embedded in policy and practice. Such concerns reflect the tensions between individualism as embedded in 
consumerist patient choice and enacting social solidarity through citizen engagement within the public sphere. Still, individualized perspectives need to be weighed against the good of the community as a whole (Callaghan and Wistow 2006).

This also implies that it is essential to be clear about why involvement is taking place; to clarify the purpose of a specific involvement activity or policy is. And what is the expected outcome? For instance, if the aim is to strengthen the responsiveness to needs and expectations of the public nationally or locally (indirect responsiveness) patients cannot be involved as proxies for the public as they do not share the views or experiences 'of the disinterested public' (Tenbensel 2010). The effect of using patients as proxies for the public is that decisions then become influenced by a sectional or particular interest, and by experiential knowledge, instead of a broader public interest and societal values. And conversely, if the aim is to strengthen the responsiveness to users of a particular service (direct responsiveness), a positive impact of involvement may not occur if members of the general public are recruited instead of patients. Thus being clear about the distinction between involving patients and involving the public is essential if the design and implementation of involvement policies are to achieve the intended goals and not be counterproductive and result in mismatched expectations.

Furthermore, greater attention should also be paid to the impact of involvement on decisions and how to measure such impacts, which can only develop with the application of a clearer comprehension of the differences between patient involvement and public involvement. It is essential that the measurement of impact of involvement is more than simply counting how many people were involved and the response to issues identified in an involvement 
activity. Explicit evidence of the impact of patient as well as public involvement would provide an incentive for involvement and create greater accountability between policy makers and decision makers in health and patients and members of the public. Clearly there is more work to do but some has already started (see Tritter and Wilford 2009).

We have explored the distinctions between patient involvement and public involvement illustrating these with reference to the English NHS and the Swedish health system. Clearly, patient involvement and public involvement in the context of public funded national health service systems is different from involvement in social health insurance or market-based systems. Similarly government and governance structures for health vary between countries. Greater attention needs to be paid to the consequences of the system level variation in the articulation, implementation and impact of patient as well as public involvement activities. The consequences on the organization of health systems and delivery of health services are likely to be significant, but as importantly true accountability, responsiveness and legitimacy can be achieved.

\section{References}

Abelson, J., Forest, P.-G., Eyles, J., Smith, P., Martin, E., Gauvin, F-P (2002) Obtaining public input for health-systems decision-making: Past experiences and future prospects. Canadian Public Administration, 45(1), pp.70-97.

Amnå, E. (2006) Playing with fire? Swedish mobilization for participatory democracy. Journal of European Public Policy, 13(4), pp.587-606.

Anderson, W., Florin, D., Gillam, S., Mountford, L. (2002) Every Voice Counts. Primary care organisations and public involvement, King's Fund, London.

Boedeltje, M. and Cornips, J. (2004) Input and Output Legitimacy in Interactive Governance. NIG Annual Work Conference 2004 Rotterdam. Available from (27-08-15): http://repub.eur.nl/pub/1750/ 
Bovens, M. (2007) Analysing and Assessing Accountability: A Conceptual Framework. European Law Journal, 13(4), pp.447-468.

Brannan, T., John, P. and Stoker, G., 2006. Active Citizenship and Effective Public Services and Programmes: How Can We Know What Really Works? Urban Studies, 43(5-6), pp.993-1008.

Brinkerhoff, D. (2003). Accountability and Health Systems: Overview, Framework, and Strategies, MD: The Partners for Health Reformplus Project, Abt Associates Inc., Maryland.

Brinkerhoff, D.W. (2004) Accountability and health systems: toward conceptual clarity and policy relevance. Health Policy and Planning, 19(6), pp.371-379.

Bristol Royal Infirmary Inquiry (2001) The Report of the Public Inquiry into children's heart surgery at the Bristol Royal Infirmary 1984-1995 Learning from Bristol. Norwich: The Stationary Office.

Brown, M.B. (2006) Survey Article: Citizen Panels and the Concept of Representation. Journal of Political Philosophy, 14(2), pp.203-225.

Cain, B.E., Dalton, R.J., Scarrow, S.E. (2003) Democracy transformed?: expanding political opportunities in advanced industrial democracies. Oxford University Press, New York.

Calhoun, CJ. (2002) "Ideal type" in Dictionary of the social sciences. Oxford University Press, New York.

Callahan, K. (2007) Citizen Participation: Models and Methods. International Journal of Public Administration, 30(11), pp.1179-1196.

Callaghan G.D., and Wistow G. (2006) Publics, patients, citizens, consumers? Power and decision making in primary health care. Public Administration Vol. 84, No. 3, 2006 (583-601)

Carman, K.L., Dardess, P., Maurer, M., Sofaer, S., Adams, K., Bechtel, C., Sweeney, J. (2013) Patient And Family Engagement: A Framework For Understanding The Elements And Developing Interventions And Policies. Health Aff. 32(2), 223-231.

Charles, C., DeMaio, S. (1993) Lay participation in health care decision making: a conceptual framework. J. Health Polit. Policy Law 18(4).

Christiaens, W., Kohn, L., Léonard, C., Denis, A., Daue, F., Cleemput, I. (2012) Models for citizen and patient involvement in health care policy - Part I: exploration of their feasibility and acceptability. (No. KCE Report s 195C). Belgian Health Care Knowledge Centre (KCE), Brussels.

Contandriopoulos, D., Denis, J.-L., Langley, A. (2004) Defining the "public" in a public healthcare system. Hum. Relat. 57(12), 1573-1596.

Coulter, A. (2013) Engaging patients in healthcare, New York: McGraw Hill Professional. 
Coulter, A. (2006) Patient engagement: why is it important? In Healthy Democracy: The Future of Involvement in Health and Social Care. Involve and NHS National Centre for Involvement.

Coulter, A. (2005) What do patients and the public want from primary care? BMJ, 331(7526), pp.1199-1201.

Coulter, A., Ellins, J. (2006) Patient-focused interventions. A review of the evidence. The Health Foundation and Picker Institute Europe.

Crawford, M., Rutter, D., Thelwall, S. (2003) User Involvement in Change Management: A Review of the Literature. Report to the National Coordinating Centre for NHS Service Delivery and Organisation R \& D (NCCSDO).

Day, P. and Klein, R. (1987) Accountabilities: Five Public Services, London: Tavistock.

Dent M. and Pahor M., (2015) Patient involvement in Europe - a comparative framework. Journal of Health Organization and Management, Vol. 29 Iss 5 pp. $546-555$

Dictionary.com (2015) "Public interest". Available at: http://dictionary.reference.com/browse/public+interest.

Docteur, E., Coulter, A. (2012) Patient-Centeredness in Sweden's Health System. An assessment and six steps for progress. The Swedish Agency for Health and Care Services Analysis, Stockholm.

Dowding, K. M. (2011) “Interests” in Encyclopedia of power. Thousand Oaks, Calif: SAGE.

Encyclopædia Britannica (2015) “Interest group”. Available at: http://www.britannica.com/topic/interest-group.

EMA (2011). The role of patients as members of the EMA Human Scientific Committees EMA/351803/2010.

http://www.ema.europa.eu/docs/en GB/document library/Other/2011/12/ WC500119614.pdf (Accessed 050416)

European Charter of patients' rights, 2002. Basis Document. Active Citizenship Network. Available from (27-08-15):

http://ec.europa.eu/health/ph_overview/co_operation/mobility/docs /health_services_co108_en.pdf

Florin, D. and Dixon, J. (2004) Public involvement in health care. BMJ, 328(7432), pp.159-161.

Forbat, L., Hubbard, G., Kearney, N. (2009) Patient and public involvement: models and muddles. J. Clin. Nurs. 18(18), 2547-2554.

Fotaki, M. (2011) Towards developing new partnerships in public services: Users as consumers, citizens and/or co-producers in health and social care in England and Sweden. Public Adm. 89(3), 933-955. 
Fraser, N. (1997) Rethinking the public sphere: A contribution to the critique of actually existing democracy, in: Justice Interruptus: Critical Reflections on the "Postsocialist" Condition. Routledge, London.

Fredriksson, M. (2013) Is patient choice democratizing Swedish primary care? Health Policy, 111(1), pp.95 - 98.

de Freitas, C., Martin, G. (2015) Inclusive public participation in health: Policy, practice and theoretical contributions to promote the involvement of marginalised groups in healthcare. Soc. Sci. Med. 135, 31 - 39.

Funk, C.L. (2000) The Dual Influence of Self-Interest and Societal Interest in Public Opinion. Polit. Res. Q. 53(1), 37-62.

Gibson, A., Britten, N. and Lynch, J. (2012) Theoretical directions for an emancipatory concept of patient and public involvement. Health: 16(5), pp.531-547.

Greenhalgh T, Peacock R (2005). Effectiveness and efficiency of search methods in systematic reviews of complex evidence: audit of primary sources. British Medical Journal;331(7524):1064-1065.

Haxby, E., Hunter, D., David, Jaggar, S.I. (2010) An introduction to clinical governance and patient safety. Oxford University Press, Oxford; New York.

Hendriks CM (2011). The Politics of Public Deliberation: Citizen Engagement and Interest Advocacy. Basingstoke: Palgrave Macmillan.

Hogg, C. (1999) Patients, power and politics: from patients to citizens, Thousand Oaks, Calif; London: SAGE.

Hopkinson, J.B. and Richardson, A. (2015) A mixed-methods qualitative research study to develop a complex intervention for weight loss and anorexia in advanced cancer: The Family Approach to Weight and Eating. Palliative medicine, 29(2), pp.164-176.

Ipsos MORI Veracity Index (2014) Available from: https://www.ipsosmori.com/Assets/Docs/Polls/VE-Dec-2014Topline_Veracity\%20Index.pdf

Ives, J., Damery, S. and Redwod, S., 2012. PPI, paradoxes and Plato: who's sailing the ship? Journal of Medical Ethics. doi:10.1136/medethics2011-100150

Lieberherr, E. (2015) Trade-Offs and Synergies: Horizontalization and legitimacy in the Swiss wastewater sector. Public Management Review, pp.1-23.

Lister, M., Pia, E. (2008) Citizenship in Contemporary Europe. Edinburgh University Press, Edinburgh. 
Marent B., Forster R. and Nowak P. (2015) Conceptualizing Lay Participation in Professional Health Care. Administration \& Society Vol. 47(7) 827850.

Martin, G.P. (2008) Representativeness, legitimacy and power in public involvement in health-service management. Social Science and Medicine, 67(11), pp.1757 - 1765.

Michels, A. and Graaf, L.D. (2010) Examining Citizen Participation: Local Participatory Policy Making and Democracy. Local Government Studies, 36(4), pp.477-491.

Mockford, C., Staniszewska, S., Griffiths, F., Herron-Marx, S. (2011) The impact of patient and public involvement on UK NHS health care: a systematic review. Int. J. Qual. Health Care 24(1):28-38.

Mulgan, R. (2000) “'Accountability': An Ever-Expanding Concept? Public Adm. 78(3), 555.

Mulgan, R. (2011) "Accountability" In Badie B, Berg-Schlosser D, Morlino L, (ed), International encyclopedia of political science. Thousand Oaks, Calif: SAGE Publications.

Myndigheten för vårdanalys (2015). Sjukt engagerad - en kartläggning av patient- och funktionshinderrörelsen. Stockholm. (see http://www.vardanalys.se/Global/Rapporter\%20pdffiler/2015/2015-4-Sjukt\%20engagerad-webb.pdf, accessed 12.2.16)

Nedlund, A-C., Garpenby, P. (2008) Kan rättvisa procedurer stärka förtroendet för prioriteringar? (No. 2008:1). PrioriteringsCentrum, Linköping.

NHS England (2014). Guide 04: Bite-size guides to patient and public participation. Budgeting for participation. Available from (27-08-15): http://www.england.nhs.uk/wp-content/uploads/2014/03/bs-guidebudget-part.pdf

NHS England (2013) Transforming participation in health and care "The NHS belongs to us all". Available at: www.england.nhs.uk.

Nordin I. (2000). Medicine, Health Care, and Philosophy 3; 297-304.

OECD (2001) Citizens as partners: information, consultation and public participation in policy-making. OECD, Paris.

OECD (2013) Government at a glance: 2013, 2013th ed. OECD, Paris.

Oliver, S.R., Rees, R.W., Clarke-Jones, L., Milne, R., Oakley, A.R., Gabbay, J., Stein, K., Buchanan, P., Gyte, G. (2008) A multidimensional conceptual framework for analysing public involvement in health services research. Health Expect. 11(1), 72-84.

Oxford Dictionaries (2015). "Interest". Available at: http://www.oxforddictionaries.com/definition/english/interest. 
Oxford Dictionaries (2015) "Public". Available at: http://www.oxforddictionaries.com/definition/english/public?q=the +public\#public_10.

Peeters, Y., Stiggelbout, A.M. (2010) Health State Valuations of Patients and the General Public Analytically Compared: A Meta-Analytical Comparison of Patient and Population Health State Utilities. Value Health 13(2), 306-309.

Pitkin, H. (1967) The Concept of Representation. University of Press, Los Angeles.

Pleasence, P., Maclean, S., 1998. The Public Interest. Legal Aid Board Research Unit.

Rothstein, B. (2009) Creating Political Legitimacy: Electoral Democracy Versus Quality of Government. American Behavioral Scientist, 53(3), pp.311330.

Rowe, G., Frewer, L.J. (2005) A Typology of Public Engagement Mechanisms. Sci. Technol. Hum. Values 30(2), 251-290.

Scharpf, F.W. (1997) Economic integration, democracy and the welfare state. J. Eur. Public Policy 4(1), 18-36.

Schlesinger, M. (2010) Choice cuts: parsing policymakers' pursuit of patient empowerment from an individual perspective. Health Econ. Policy Law 5(Special Issue 03), 365-387.

Schmidt, V.A. (2013) Democracy and Legitimacy in the European Union Revisited: Input, Output and "Throughput." Polit. Stud. 61(1), 2-22.

Snyder, H. (2014) Patient Involvement - A Service Perspective. Institutionen för ekonomisk och industriell utveckling, Tekniska högskolan, and Kvalitetsteknik, Linköping University.

Socialstyrelsen (n.d.). Samverka med patienten (Collaborating with Patients)

https://www.socialstyrelsen.se/patientsakerhet/ledningssystem/samverkam edpatienten (Accessed 2016-02-12)

Staley K. J (2003). There is no paradox with PPI in research. Med Ethics March 2013 Vol 39 No 3.

Suchman, M.C. (1995) Managing Legitimacy: Strategic and Institutional Approaches. Acad. Manage. Rev. 20(3), 571-610.

Swers, M.L. (2005) Connecting Descriptive and Substantive Representation: An Analysis of Sex Differences in Cosponsorship Activity. Legis. Stud. Q. 30(3) 407-432.

Tenbensel T. Virtual special issue introduction: Public participation in health policy in high income countries - A review of why, who, what, which, and where? Social Science \& Medicine. 2010;71:1537-1540. 
The Centre for Public Scrutiny (2007) The anatomy of accountability: how the national health service answers to the people. Available at: http://www.cfps.org.uk/domains/cfps.org.uk/local/media/uploads/6 6.pdf.

Trappenburg, M. (2005) Fighting Sectional Interests in Health Care. Health Care Analysis, 13(3), pp.223-237.

Tritter, J.Q. (2010) Globalisation, markets, and healthcare policy: redrawing the patient as consumer. Routledge, Abingdon, Oxon; New York, NY.

Tritter, J.Q. (2009) Revolution or evolution: the challenges of conceptualizing patient and public involvement in a consumerist world. Health Expect. 12(3), 275-287.

Tritter, J. Q. and Wilford, S. (2009) Evaluating the impact of Personal and Public Involvement: Piloting a PPI Evaluation Framework in Northern Ireland.

Coventry, NHS National Centre for Involvement.

Urbinati, N., Warren, M.E. (2008) The Concept of Representation in Contemporary Democratic Theory. Annu. Rev. Polit. Sci. 11(1), 387412.

Van Thiel, G., Stolk, P. (2013) Background Paper 8.5. Patient and Citizen Involvement. Available from (27-08-15): http://www.who.int/medicines/areas/priority_medicines/BP8_5Stak eholder.pdf

Warren ME. (2008) Citizen representatives. In Designing Deliberative Democracy The British Columbia Citizens' Assembly, (eds.) Warren, ME., Pearse, H. Cambridge University Press; Cambridge.

Warsh, J. (2014) PPI: Understanding the Difference Between Patient and Public Involvement. Am. J. Bioeth. 14(6), 25-26. 